\title{
Cognitive Decline in Patients with Chronic Hydrocephalus and Normal Aging: 'Growing into Deficits'?
}

\author{
Marlijn H. de Beer ${ }^{a}$ b Philip Scheltens ${ }^{a}$ \\ a Department of Neurology and Alzheimer Center, VU University Medical Center and \\ Neuroscience Campus Amsterdam, Amsterdam, and b HagaZiekenhuis (Haga Hospital), \\ The Hague, The Netherlands
}

\section{Key Words}

Dementia · Hydrocephalus · Cerebrospinal fluid · Alzheimer's disease

\begin{abstract}
Background/Aim: To explore the theory of 'growing into deficits', a concept known from developmental neurology, in a series of cases with chronic hydrocephalus $(\mathrm{CH})$. Methods: Patients were selected from the Amsterdam Dementia Cohort and underwent extensive dementia screening. Results: Twelve patients with $\mathrm{CH}$ were selected, in whom Alzheimer's disease was considered unlikely, based on biomarker information and follow-up. Mean Mini-Mental State Examination score was 24 (range 7-30). Most patients were functioning on a level of mild dementia [Clinical Dementia Rating score of 0.5 in 8/11 (66.7\%) patients]. On neuropsychological examination, memory and executive functions, as well as processing speed were most frequently impaired. Conclusion: In our opinion, the theory of 'growing into deficits' shows a parallel with the clinical course of $\mathrm{CH}$ and normal aging when Alzheimer's disease was considered very unlikely, because most of these patients were functioning well for a very large part of their lives. The altered cerebrospinal fluid dynamics might make the brain more vulnerable to aging-related changes, leading to a faster cognitive decline in $\mathrm{CH}$ patients compared to healthy subjects, especially in case of concomitant brain damage such as traumatic brain injury or meningitis.


de Beer and Scheltens: Cognitive Decline in Patients with Chronic Hydrocephalus and Normal Aging: 'Growing into Deficits'?

\section{Introduction}

Enlargement of the ventricular system is a common finding on neuroimaging in patients visiting a memory clinic. This finding raises a lot of questions for the clinician about the underlying etiology of the ventricular enlargement, as well as the clinical relevance of this finding related to the cognitive symptoms of the patient.

Progressive enlargement of the ventricular system is found in a number of neurodegenerative diseases, such as Alzheimer's disease (AD), vascular dementia and progressive supranuclear palsy, but specifically in patients with chronic hydrocephalus (CH) [1]. All of these conditions share the clinical symptoms of cognitive decline and gait disturbances.

$\mathrm{CH}$ is a complex condition characterized by ventriculomegaly, with excessive accumulation of cerebrospinal fluid (CSF), in the absence of a significant elevation or chronic lowgrade elevation of intracranial pressure $[2,3]$. $\mathrm{CH}$ is clinically characterized by cognitive decline and gait disturbances and to a lesser extent also by urinary incontinence [4]. The term ' $\mathrm{CH}$ ' is used for a wide spectrum of conditions associated with ventricular enlargement, including normal pressure hydrocephalus (NPH) [4], compensated congenital hydrocephalus, adult-onset aqueduct stenosis and acquired hydrocephalus [2].

NPH, as first described by Hakim and Adams [5], encompasses two different types of patients. On the one hand, cases with acquired or 'secondary hydrocephalus', with a clear causative factor, such as trauma, meningitis or subarachnoid hemorrhage, in which failing absorptive mechanisms lead to disturbances in CSF dynamics. This category also includes patients with decompensated congenital hydrocephalus or late-onset aqueduct stenosis. On the other hand, it includes patients without an evident causative factor, referred to as 'idiopathic NPH'. Typically, CSF pressure in NPH will be in the normal range when measured by lumbar puncture. However, CSF pressure in NPH is not constant throughout $24 \mathrm{~h}$, and is associated with pressure waves and an increase in CSF pressure over the night [6].

For the sake of completeness, NPH also includes 'ex vacuo hydrocephalus', defined as ventricular enlargement due to cerebral atrophy and is therefore unrelated to disturbances in CSF dynamics $[2,7]$. Nevertheless, this enlargement is often found accidently and most importantly without the clinical symptoms.

In all forms of $\mathrm{CH}$, the clinical course is influenced by changes in the brain associated with normal aging [2], which by itself is associated with a decline in cognitive function and functional reserves as well [8-10].

In developmental neurology, the concept called 'growing into deficits' is known as the phenomenon that the effects of early brain damage on development are cumulative as more functions are expected to mature, leading to global neurological disorders in later life, such as mental retardation and impaired motor functions [11-14]. The same concept may be applicable to $\mathrm{CH}$, because patients may have done well despite the brain changes for a long time, but may experience cognitive decline when combined with changes associated with aging, especially since additional neurodegenerative causes may be ruled out by the use of Alzheimerspecific biomarkers.

The aim of this study was to explore this theory of 'growing into deficits' in a series of cases with $\mathrm{CH}$.

\section{Methods}

Cases

We selected patients from the Amsterdam Dementia Cohort [15] who visited the VU University Medical Center between July 2001 and February 2016. Inclusion criteria were (1) 
clinical symptoms of cognitive decline and ventricular enlargement on magnetic resonance imaging (MRI) at baseline visits and (2) medical history of childhood hydrocephalus, aqueduct stenosis, congenital posterior fossa abnormalities or other posterior fossa lesions having required surgical treatment in the past. Patients were excluded in case of (1) recent (less than 6 months) medical history of subarachnoid hemorrhage or head trauma, or (2) biomarkers indicating neurodegenerative disease. Ventricular enlargement on MRI was defined as ventricular dilation out of proportion to the cortical sulcal enlargement, with ballooning of the frontal horns and enlargements of the temporal horns [2].

All patients underwent extensive standardized dementia screening, including medical history, physical and neurological examination, electroencephalography, MRI and routine laboratory tests, described elsewhere [15]. CSF was obtained by lumbar puncture.

Diagnoses were made by consensus in a multidisciplinary team according to the current international diagnostic criteria.

The standardized workup of the Alzheimer center was approved by the Medical Ethical Review Committee of the VU University Medical Center. All patients provided written informed consent for the use of their clinical data for research purposes.

\section{Cerebrospinal Fluid}

CSF was obtained by lumbar puncture between the L3/L4 or L4/L5 intervertebral space, using a 25-gauge spinal needle. A lumbar puncture was indicated in cases where AD-specific CSF biomarkers were needed. Spinal fluid pressure measurements and spinal fluid tap tests were not performed. CSF was routinely tested for leukocytes, total protein and glucose levels. The following CSF biomarkers were analyzed: $\mathrm{A} \beta_{42}$ (reference level $>550$ $\mathrm{pg} / \mathrm{ml}$ ), total tau (reference level $<375 \mathrm{pg} / \mathrm{ml}$ ) and phosphorylated tau-181 (reference level $<52 \mathrm{pg} / \mathrm{ml}$ ).

\section{Neuropsychological Examination}

We used the Mini-Mental State Examination (MMSE) [16] and Cambridge Cognitive Examination (CAMCOG) [17] as measures for global cognition. On neuropsychological test examination, the following domains were tested: memory functions, attention, language, executive functions (including processing speed) and visuoconstructive functions. Clinical Dementia Rating (CDR) [18] was used as a measure for the global degree of functioning.

\section{Results}

Cases

A total of 45 patients with hydrocephalus were identified from our Amsterdam Dementia Cohort. A total of 15/45 cases fulfilled the inclusion criteria. Three cases were additionally excluded as a result of their CSF biomarkers compatible with AD. In the remaining 12 cases, $\mathrm{AD}$ has been considered very unlikely due to (1) normal CSF values of $A \beta$, and/or (2) normal CSF values of total tau and phosphorylated tau, and/or (3) no signs of neurodegeneration on MRI, and/or (4) a clinical phenotype not compatible with AD. Clinical characteristics of all cases are displayed in table 1 .

Mean age was 63.6 (range 39.7-72.5) years, and 10/12 (83.3\%) were males. Mean duration of cognitive complaints until diagnosis was $49.9 \pm 43.9$ months. A total of $9 / 12$ $(75 \%)$ of cases had some degree of gait disturbances. Figure 1 displays MRI of a typical $\mathrm{CH}$ case. 
Fig. 1. MRI of case No. 11 with the clinical picture of $\mathrm{CH}$ due to congenital hydrocephalus. a Axial T2weighted display of supratentorial hydrocephalus. b Axial multiplanar reconstruction FLAIR display of supratentorial hydrocephalus. c Coronal multiplanar reconstruction display of supratentorial hydrocephalus with giant arachnoid cyst in the posterior fossa. The impression of hippocampal atrophy exists as a result of bilateral severely widened temporal horns of the lateral ventricles. d Sagittal multiplanar reconstruction display of supratentorial hydrocephalus with giant arachnoid cyst in the posterior fossa.
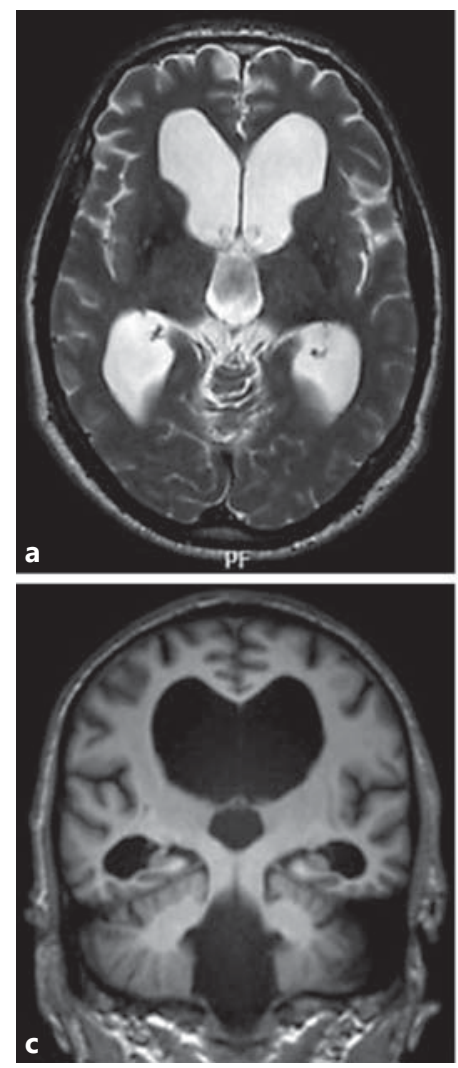

\section{Cerebrospinal Fluid}

A total of 8/12 patients underwent lumbar puncture for collection of AD-specific CSF biomarkers. Results are displayed in table 1. In case No. 11, a lumbar puncture was contraindicated due to a giant arachnoid cyst in the posterior fossa.

\section{Neuropsychological Examination}

Table 2 represents the neuropsychological results of all cases. On neuropsychological examination, memory and executive functions, as well as processing speed were most frequently impaired. Mean MMSE score was 24 (range 7-30). CAMCOG scores were available from $7 / 12$ patients with a mean score of 72 (range 35-95). The global degree of functioning was classified as CDR score of 0.5 in the majority of patients $(8 / 11,66.7 \%)$.

\section{Discussion}

We present 12 cases of $\mathrm{CH}$ from our memory clinic, with cognitive decline and gait disturbances, in whom $\mathrm{AD}$ as the underlying disease had been made highly unlikely or even excluded with the use of biomarkers. All patients were functioning on the level of mild to moderate dementia, for which they sought medical help at our memory clinic, and the majority of them also suffered from gait disturbances. We found that memory and executive functions as well as an impaired processing speed, were most commonly affected on neuropsychological test examination. Remarkably, all had been functioning very well for a large part of their lives, despite the fact that their brain abnormalities had been present for a long time in most of them. 
de Beer and Scheltens: Cognitive Decline in Patients with Chronic Hydrocephalus and Normal Aging: 'Growing into Deficits'?

Table 1. Clinical characteristics of all cases

\begin{tabular}{|c|c|c|c|c|c|c|c|c|}
\hline \multirow[t]{2}{*}{ Case } & \multirow{2}{*}{$\begin{array}{l}\text { Age, } \\
\text { years }\end{array}$} & \multirow[t]{2}{*}{ Sex } & \multirow[t]{2}{*}{ Past medical history } & \multirow[t]{2}{*}{ Clinical signs } & \multicolumn{3}{|c|}{ CSF biomarkers, $\mathrm{pg} / \mathrm{ml}$} & \multirow[t]{2}{*}{ Magnetic resonance imaging } \\
\hline & & & & & $\mathrm{A} \beta$ & t-Tau & p-Tau & \\
\hline 1 & 61 & M & $\begin{array}{l}\text { Childhood hydrocephalus, } \\
\text { traumatic brain injury }\end{array}$ & $\begin{array}{l}\text { Memory complaints, } \\
\text { difficulties in word } \\
\text { finding and } \\
\text { concentration }\end{array}$ & - & - & - & $\begin{array}{l}\text { Ventriculomegaly and known } \\
\text { posttraumatic lesion in the left } \\
\text { temporal lobe }\end{array}$ \\
\hline 2 & 40 & M & $\begin{array}{l}\text { Mesial temporal sclerosis } \\
\text { with epilepsy }\end{array}$ & Cognitive decline, apathy & 712 & 241 & 27 & $\begin{array}{l}\text { Chronic supratentorial } \\
\text { ventriculomegaly due to } \\
\text { aqueductal stenosis }\end{array}$ \\
\hline 3 & 70 & M & Hydrocephalus & $\begin{array}{l}\text { Unsteady gait, memory } \\
\text { complaints }\end{array}$ & 383 & 150 & 19 & $\begin{array}{l}\text { Supratentorial ventriculomegaly } \\
\text { and leukoaraiosis, no signs of } \\
\text { aqueductal stenosis }\end{array}$ \\
\hline 4 & 59 & $\mathrm{~F}$ & Hydrocephalus & $\begin{array}{l}\text { Gait disturbance, } \\
\text { memory complaints, } \\
\text { impaired concentration, } \\
\text { depressive mood }\end{array}$ & 997 & 229 & 39 & $\begin{array}{l}\text { Quadriventricular } \\
\text { communicating hydrocephalus, } \\
\text { no signs of aqueductal stenosis }\end{array}$ \\
\hline 5 & 70 & M & $\begin{array}{l}\text { Traumatic brain injury in } \\
\text { childhood }\end{array}$ & $\begin{array}{l}\text { Memory complaints, } \\
\text { lack of interest }\end{array}$ & 766 & 272 & 39 & $\begin{array}{l}\text { Triventricular hydrocephalus } \\
\text { with aqueductal stenosis }\end{array}$ \\
\hline 6 & 66 & M & $\begin{array}{l}\text { Bacterial meningitis in } \\
\text { childhood, hypertension, } \\
\text { TIA }\end{array}$ & $\begin{array}{l}\text { Memory complaints, } \\
\text { difficulties in planning } \\
\text { and problem-solving, } \\
\text { unsteady gait }\end{array}$ & - & - & - & $\begin{array}{l}\text { Quadriventricular } \\
\text { communicating hydrocephalus }\end{array}$ \\
\hline 7 & 64 & M & Bacterial meningitis & $\begin{array}{l}\text { Memory complaints, gait } \\
\text { disturbance, impaired } \\
\text { vision and hearing }\end{array}$ & 370 & 255 & 16 & $\begin{array}{l}\text { Quadriventricular } \\
\text { communicating hydrocephalus }\end{array}$ \\
\hline 8 & 73 & M & $\begin{array}{l}\text { Mild Arnold Chiari } \\
\text { malformation }\end{array}$ & $\begin{array}{l}\text { Memory complaints, } \\
\text { compulsive acts, gait } \\
\text { disturbance }\end{array}$ & 422 & 300 & 43 & $\begin{array}{l}\text { Ventriculomegaly with narrow } \\
\text { foramen magnum and mild } \\
\text { protrusion of cerebellar tonsils }\end{array}$ \\
\hline 9 & 59 & M & Congenital hydrocephalus & $\begin{array}{l}\text { Memory complaints, lack } \\
\text { of interest, difficulties in } \\
\text { planning, unsteady gait }\end{array}$ & 892 & 124 & 24 & Ventriculomegaly \\
\hline 10 & 67 & $\mathrm{~F}$ & $\begin{array}{l}\text { Traumatic brain injury in } \\
\text { childhood }\end{array}$ & $\begin{array}{l}\text { Memory complaints, } \\
\text { disorientation, unsteady } \\
\text { gait }\end{array}$ & - & - & - & $\begin{array}{l}\text { Chronic supratentorial } \\
\text { ventriculomegaly, no signs of } \\
\text { aqueductal stenosis }\end{array}$ \\
\hline 11 & 72 & M & $\begin{array}{l}\text { Congenital hydrocephalus } \\
\text { with giant arachnoid cyst } \\
\text { posterior fossa }\end{array}$ & $\begin{array}{l}\text { Memory complaints, lack } \\
\text { of interest, difficulties in } \\
\text { planning and problem- } \\
\text { solving, gait disturbance }\end{array}$ & - & - & - & $\begin{array}{l}\text { Supratentorial hydrocephalus } \\
\text { with giant arachnoid cyst } \\
\text { posterior fossa }\end{array}$ \\
\hline 12 & 64 & M & $\begin{array}{l}\text { Hydrocephalus due to } \\
\text { mesencephalic tumor } \\
\text { requiring surgical } \\
\text { treatment (third } \\
\text { ventriculostomy) }\end{array}$ & $\begin{array}{l}\text { Memory complaints, } \\
\text { difficulties in planning } \\
\text { and problem-solving, } \\
\text { unsteady gait }\end{array}$ & 1,331 & 501 & 65 & $\begin{array}{l}\text { Supratentorial hydrocephalus } \\
\text { with intact flow through } \\
\text { ventriculostomy (3rd ventricle) } \\
\text { and Monro's foramen }\end{array}$ \\
\hline
\end{tabular}

$\mathrm{t}-\mathrm{Tau}=$ Total tau; $\mathrm{p}-\mathrm{Tau}=$ phosphorylated tau.

Previous studies have shown that cognitive changes in $\mathrm{CH}$ predominantly include inattention, memory complaints, apathy, emotional lability, and disinhibition.[2] Disturbances in memory and executive functions including slowed mental processing speed are the most common findings on neuropsychological examination [2,19].

Gait disturbances are a common finding in $\mathrm{CH}$ patients, varying from postural instability to 'magnetic gait' and akinetism [2]. One explanation for gait disturbances in $\mathrm{CH}$ might be the proximity to the lateral ventricles of the axons innervating the legs. These axons might become vulnerable to compression by the increasing ventricular size $[2,20]$. 
Table 2. Neuropsychological test results of all cases

\begin{tabular}{rrrll}
\hline Case & \multicolumn{2}{l}{ MMSE } & CAMCOG & Neuropsychological test examination \\
\hline 1 & - & - & Impaired processing speed, memory function and concentration & 0.5 \\
2 & 26 & - & Impaired memory function & 0.5 \\
3 & 30 & - & Unknown & 0.5 \\
4 & 24 & - & Disturbance in memory and executive functions & 0.5 \\
5 & 28 & - & Disturbance in memory function & 0.5 \\
6 & 29 & 93 & Impaired memory functions & 1 \\
7 & 21 & 58 & Severe disturbances in all cognitive domains, including processing speed & 2 \\
8 & 7 & 35 & Disturbances in all cognitive domains & 0.5 \\
9 & 22 & 74 & Disturbance in memory and executive functions & 0.5 \\
10 & 27 & 79 & Disturbance in memory, executive and visuoconstructive functions \\
11 & 21 & 69 & Impaired processing speed, disturbance in memory and executive functions & 1 \\
12 & 28 & 95 & Impaired processing speeds, disturbance in memory function & 0.5 \\
\hline
\end{tabular}

The pathogenesis of $\mathrm{CH}$ is not fully understood yet. A widened ventricular system by itself does not seem to be a sufficient explanation for the cognitive decline, as evidenced by the fact that most patients had functioned quite well with $\mathrm{CH}$ for a long time. Moreover, ventriculomegaly is frequently found as an incidental finding on MRI, and has so far been asymptomatic. Furthermore, a study performed by Graff-Radford et al. [21] showed that ventricular size might remain unchanged despite dramatic improvement of symptoms and normalization of intracranial pressure in patients with obstructive hydrocephalus after successful endoscopic third ventriculostomy. Therefore, other mechanisms must be involved in disturbing the equilibrium of CSF dynamics, leading to cognitive deterioration in later life.

The clinical course of $\mathrm{CH}$ is influenced by aging-related changes in the brain, causing dysfunction at a certain age. These changes encompass hydrodynamic alterations in CSF flow and reduced compliance of the spinal subarachnoid space $[2,22]$. Previous studies have suggested that aqueductal CSF flow might be higher and that cervical CSF flow might be lower in $\mathrm{CH}$ patients compared to healthy individuals. The large aqueductal flow is thought to cause an increased transcerebral mantle pressure gradient, leading to ventricular dilation [23]. Another possible mechanism causing ventriculomegaly is an increased CSF outflow resistance [6].

Degenerative vascular changes in the brain parenchyma occurring with increasing age are also suggested to play an important role in the development of ventricular enlargement $[2,24,25]$. The choroid plexus has a large influence on the production of antioxidant enzymes and transport of vitamins C and E into the CSF; unfortunately, these neuroprotective functions of the choroid plexus decrease with aging $[2,26]$. Besides, the absorptive mechanisms in the arachnoid villi show reduced capacity with increasing age [2, 3].

According to Pascal's principle that represents only diffusion and no flow, the intracranial pressure will be uniform in the ventricular system and subarachnoid space [1]. However, physiological or pathological events might disturb CSF absorption and reduction in CSF turnover, causing ventriculomegaly.

In our study, 3 patients suffered respectively from traumatic brain injury (case 1), bacterial meningitis (case 7) and a mesencephalic tumor (case 12), all at least 1.5 years prior to onset of cognitive decline. One could imagine that these events could have possibly induced decompensation of the above-mentioned mechanisms. Furthermore, an impaired CSF turnover could result in a reduced clearance of neurotoxins from the central nervous system, like large proteins such as $A \beta$ [27]. This might be the case in our 3 patients with a reduced CSF level of $A \beta$ (with normal levels of tau and phosphorylated tau) (case No. 3, 7 and 8). 
de Beer and Scheltens: Cognitive Decline in Patients with Chronic Hydrocephalus and Normal Aging: 'Growing into Deficits'?

Normal aging is associated with a decline in cognitive function as well as functional reserves $[8,9]$. Neuroimaging studies of cognitively healthy older subjects have shown volume loss and loss of white matter structural integrity, which may be associated with cognitive decline [28].

The main limitation of our study is the retrospective observational design. With this case series, we have tried to provoke a thought about the possible mechanism of cognitive decline in $\mathrm{CH}$ patients. This hypothesis would be stronger when supported by a prospective study, including a matched control group with $\mathrm{CH}$ without cognitive change and with all CSF and imaging biomarker data available.

Another limitation of this study is the fact that information about the hemodynamic alterations in CSF flow is missing.

Because of the retrospective observational study design, hydrocephalus was not initially considered as a cause of cognitive decline. Lumbar punctures were performed just to collect CSF for analysis of AD-specific biomarkers. Therefore, the spinal fluid tap test and CSF pressure measurements were not performed and unfortunately, data about possible improvement of gait disturbances are lacking. Because 25-gauge needles were used for lumbar punctures, CSF pressure measurements would have been unreliable anyway.

In our opinion, the theory of 'growing into deficits' shows a parallel with the clinical course of $\mathrm{CH}$ and normal aging. One should bear in mind that the ventricular enlargement by itself does not seem to be a sufficient explanation for the clinical picture alone, because most of these patients are functioning well for a very large part of their lives. However, at a certain point, the equilibrium of CSF dynamics decompensates, leading to cognitive symptoms and gait disturbances. When $\mathrm{AD}$ as a possible explanation for this cognitive decline has been ruled out or made highly unlikely, there must be another factor that is responsible for the disturbed equilibrium. The altered CSF dynamics might make the brain more vulnerable to agingrelated changes, leading to a faster cognitive decline in $\mathrm{CH}$ patients compared to healthy subjects, especially in case of concomitant brain damage such as traumatic brain injury or meningitis.

Therefore, we suggest that in all patients visiting a memory clinic with the combination of cognitive complaints, gait disturbances and ventriculomegaly on MRI suspecting $\mathrm{CH}$, this theory of 'growing into deficits' should be considered as a possible explanation for the cognitive decline, when AD has been ruled out and hydrodynamic alterations in CSF flow have been excluded.

\section{Statement of Ethics}

The standardized workup of the Alzheimer center was approved by the Medical Ethical Review Committee of the VU University Medical Center. All patients provided written informed consent for the use of their clinical data for research purposes.

\section{Disclosure Statement}

Marlijn H. de Beer reports no disclosures. Philip Scheltens has received grant support (for the institution) from GE Healthcare, Danone Research, Piramal and MERCK. In the past 2 years, he has received consultancy/speaker fees (paid to the institution) from Lilly, GE Healthcare, Novartis, Forum, Sanofi, Nutricia, Probiodrug and EIP Pharma. All funds are paid to his institution. 


\section{References}

1 Missori P, Currà A: Progressive cognitive impairment evolving to dementia parallels parieto-occipital and temporal enlargement in idiopathic chronic hydrocephalus: a retrospective cohort study. Front Neurol 2015; $6: 1-7$.

-2 Edwards RJ, Dombrowski SM, Luciano MG, Pople IK: Chronic hydrocephalus in adults. Brain Pathol 2004;14: 325-336.

3 Satish Krishnamurthy JL: New concepts in the pathogenesis of hydrocephalus. Transl Pediatr 2014;3:185194.

4 Hakim CA, Hakim R, Hakim S: Normal-pressure hydrocephalus. Neurosurg Clin N Am 2001;12:761-773.

5 Hakim S, Adams R: The special clinical problem of symptomatic hydrocephalus with normal cerebrospinal fluid pressure. Observations on cerebrospinal fluid hydrodynamics. J Neurol Sci 1965;2:307-327.

6 Silverberg GD, Mayo M, Saul T, Rubenstein E, McGuire D: Alzheimer's disease, normal-pressure hydrocephalus, and senescent changes in CSF circulatory physiology: a hypothesis. Lancet Neurol 2003;2:506-511.

7 Bradley W: Diagnostic tools in hydrocephalus. Neurosurg Clin N Am 2001;12:661-684.

8 Czernochowski D, Fabiani M, Friedman D: Use it or lose it? SES mitigates age-related decline in a recency/ recognition task. Neurobiol Aging 2008;29:945-958.

-9 Fabiani M, Low KA, Wee E, Sable JJ, Gratton G: Reduced suppression or labile memory? Mechanisms of inefficient filtering of irrelevant information in older adults. J Cogn Neurosci 2006;18:637-650.

10 Stern Y: What is cognitive reserve? Theory and research application of the reserve concept. J Int Neuropsychol Soc 2002;8:448-460.

11 Dulac O, Lassonde M, Sarnat H: Handbook of Clinical Neurology. Pediatric Neurology, Part II, ed 1. Amsterdam, Elsevier Inc, 2013.

12 Prins P, Braet C: Handboek Klinische Ontwikkelingspsychologie, ed 2. Houten, Bohn Stafleu Van Loghum, 2014.

13 Fenichel G: Clinical Pediatric Neurology: A Signs and Symptoms Approach, ed 6. Philadelphia, Elsevier Health Sciences, 2009.

14 Aarsen FK, Paquier PF, Reddingius RE, Streng IC, Arts WFM, Evera-Preesman M, et al: Functional outcome after low-grade astrocytoma treatment in childhood. Cancer 2006;106:396-402.

15 Van Der Flier WM, Pijnenburg YAL, Prins N, Lemstra AW, Bouwman FH, Teunissen CE, et al: Optimizing patient care and research: the Amsterdam Dementia Cohort. J Alzheimers Dis 2014;41:313-327.

-16 Folstein MF, Folstein SE, McHugh PR: 'Mini-mental state'. A practical method for grading the cognitive state of patients for the clinician. J Psychiatr Res 1975;12:189-198.

17 Derix M, Hofstede A, Teunisse S, Hijdra A, Walstra G, Weinstein H, et al: The Dutch version of the Cambridge Examination for Mental Disorders of the Elderly with automatic data processing. Tijdschr Gerontol Geriatr 1991;22:143-150.

18 Hughes C, Berg L, Danziger W, Coben L, Martin R: A new clinical scale for the staging of dementia. Br J Psychiatry $1982 ; 566-572$

19 Iddon JL, Pickard JD, Cross JJ, Griffiths PD, Czosnyka M, Sahakian BJ: Specific patterns of cognitive impairment in patients with idiopathic normal pressure hydrocephalus and Alzheimer's disease: a pilot study. J Neurol Neurosurg Psychiatry 1999;723-732.

-20 Yakolev P: Paraplegias of hydrocephalics: a clinical note and interpretation. Am J Ment Defic 1947;51:561576.

-21 Graff-Radford NR, Godersky JC: Normal pressure hydrocephalus. Onset of gait abnormality before dementia predicts good surgical outcome. Arch Neurol 1986;43:940-942.

22 Bateman GA: Vascular compliance in normal pressure hydrocephalus. Am J Neuroradiol 2000;21:1574-1585. Greitz D, Hannerz J, Rahn T, Bolander H, Ericsson A: MR imaging of cerebrospinal fluid dynamics in health and disease. On the vascular pathogenesis of communicating hydrocephalus and benign intracranial hypertension. Acta Radiol 1994;35:204-211.

-24 Boon AJ, Tans JT, Delwel EJ, Egeler-Peerdeman SM, Hanlo PW, Wurzer HA, et al: Dutch Normal-Pressure Hydrocephalus Study: the role of cerebrovascular disease. J Neurosurg 1999;90:221-226.

25 Bradley W, Whittemore A, Kortman K, Watanabe A, Homyak M, Teresi L, et al: Marked cerebrospinal fluid void: indicator of successful shunt in patients with suspected normal-pressure hydrocephalus. Radiology 1991; 178:459-466.

-26 Serot J, Béné M, Faure G: Choroid plexus, aging of the brain, and Alzheimer's disease. Front Biosci 2003; 8:s515-s521.

27 Preston JE: Ageing choroid plexus-cerebrospinal fluid system. Microsc Res Tech 2001;52:31-37.

-28 Caserta MT, Bannon Y, Fernandez F, Giunta B, Schoenberg MR, Tan J: Normal brain aging, clinical, immunological, neuropsychological, and neuroimaging features. Int Rev Neurobiol 2009;84:1-19. 